\title{
PRIMERAS GAFAS EN LA PINTURA Y MINIATURA DEL S. XIV
}

\author{
BARBÓN JJ ${ }^{1}$, SAMPEDRO A ${ }^{1}$, ÁLVAREZ SUÁREZ ML ${ }^{2}$
}

Los anteojos parece que fueron inventados a finales del s. XIII en el sur de Europa, probablemente en la región de Venecia, resultando muy improbable un origen más antiguo aunque existe una gran controversia al respecto. La observación de algunas imágenes datadas de pocos años más tarde, tomadas de retratos y miniaturas del s. XIV, nos aportan muchos datos sobre la vida cotidiana de las gentes del medievo entre los que se encuentra las primeras ilustraciones confirmando el uso de gafas. Gracias a que los pintores añadían gafas a sus personajes, al margen de la época histórica en que se desarrollaba la escena (que podía ser bíblica), se puede documentar de forma incuestionable el uso de antiparras en el s. $\mathrm{XIV}$, aunque será a lo largo de la centuria siguiente, sobre todo en su segunda mitad, cuando se hacen más numerosas las representaciones pictóricas de personajes con gafas, lo que indica su rápida expansión como ayuda visual. La forma más corriente de anteojos adoptada en estos primeros tiempos fue la de dos ramas unidas en un extremo por medio de un clavo, de ahí que en Francia fueran conocidas como clouantes (de clou, clavo); en Italia las llamaron occhiali y en España antojos o antiparras.

Resulta bastante conocido que la pintura más antigua donde aparecen unos anteojos es el Retrato del cardenal Hugo de Provenza, debido al pintor Tomasso da Modena (Modena, 1325/26 - antes de 1379) que se encuentra en la Iglesia de San Nicolás de Treviso. El fresco fue realizado a mediados del s. XIV, sobre 1352, y muestra al Cardenal, en su escritorio, con unas gafas echas con un par de aros unidas con un clavo. En la misma Iglesia también pintó en fecha aproximada al Cardenal Nicolas de Rouen leyendo un libro con la ayuda de una lupa provista de un mango.

Las otras dos imágenes las hemos extraído de dos libros iluminados en el s. XIV, objetos de lujo encargados por la Nobleza y por la Iglesia medieval que constituyen una de las expresiones artísticas más importantes en Europa entre los siglos VIII al $\mathrm{XV}$. Ambas fueron realizadas en estilo gótico internacional, vigente aproximadamente entre 1380 y 1420, y que se caracteriza por la utilización de líneas onduladas y sinuosas, la recreación de figuras alargadas, con cierta afectación en las posturas, y el uso de un brillante colorido que potencia la expresividad del cuadro.

En Las Muy Bellas Horas de Nuestra Señora de Jean de Berry aparece una miniatura titulada «Jesús entre los doctores», realizada por el llamado Maestro de Paramento, donde un anciano, que se ha puesto en pie para señalar al niño Jesús el texto de un libro abierto, lleva unas antiparras. Los Libros de Horas eran breviarios para laicos que contenían salmos y oraciones que se debían de recitar a unas horas precisas, las horas canónicas. La mayoría de estos libros fueron producidos en los s. XIV y XV, solían estar profusamente ilustrados con grandes

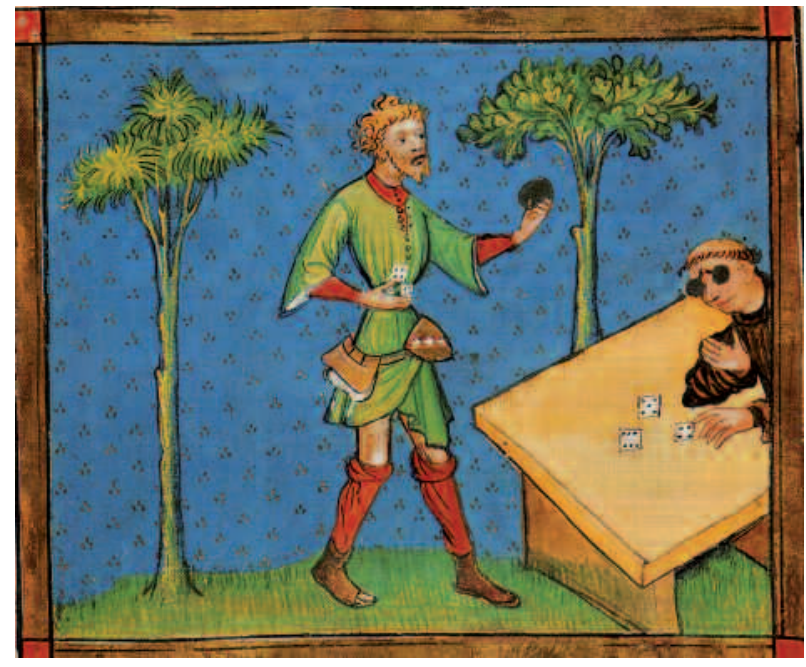

El Libro del Juego de Ajedrez de Ammenhausen. Biblioteca Nacional de Rusia. San Petersburgo.

\footnotetext{
${ }^{1}$ Licenciado en Oftalmología. Hospital San Agustín de Avilés. Asturias. España. E-mail: jjbarbon@telecable.es

2 Doctora en Oftalmología. Hospital Álvarez-Buylla de Mieres. Asturias. España.
} 


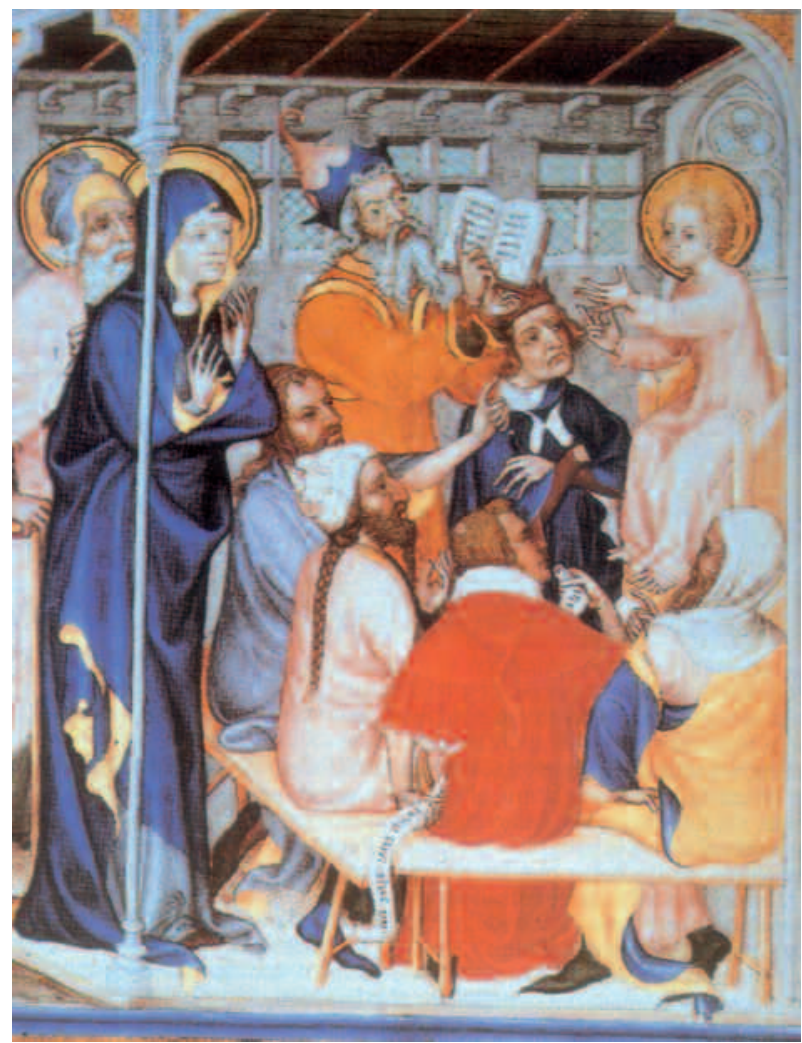

Les très belles heures de Nôtre-Dame. Biblioteca Nacional. París, Francia.

iniciales, multitud de iluminaciones y decoraciones en los márgenes. Jean de Berry (1340-1416), duque de Berry, era una especie de Virrey en el centro y sur de Francia que desarrolló una gran labor como mecenas, coleccionista de arte y bibliófilo. Los Libros de Horas eran una parte importante de su colección entre los que se encontraban, además de estas Muy Bellas Horas, Las Grandes Horas, Las Bellas Horas y, quizá el más conocido, Las Muy Ricas Horas, realizado por los hermanos Limbourg. Los maestros pintores que trabajaron para el duque de Berry revolucionaron el arte de la iluminación, a la que dotan de una mayor fuerza expresiva, con movimiento y una primitiva perspectiva.

Las Muy Bellas Horas se componía a su vez de 3 partes: un Libro de Horas (Les Très Belles Heures de Nôtre-Dame), un misal (Livre d'heures de TurínMilan) y un libro de oraciones (Livre de Prières de Turín). Las primeras ilustraciones se empezaron hacia 1380, pintadas por Maestro del Paramento de Narbona, activo entre 1375 y 1400, que creó figuras elegantes en movimiento y completó las miniaturas más importantes. El Libro de Horas fue presentado

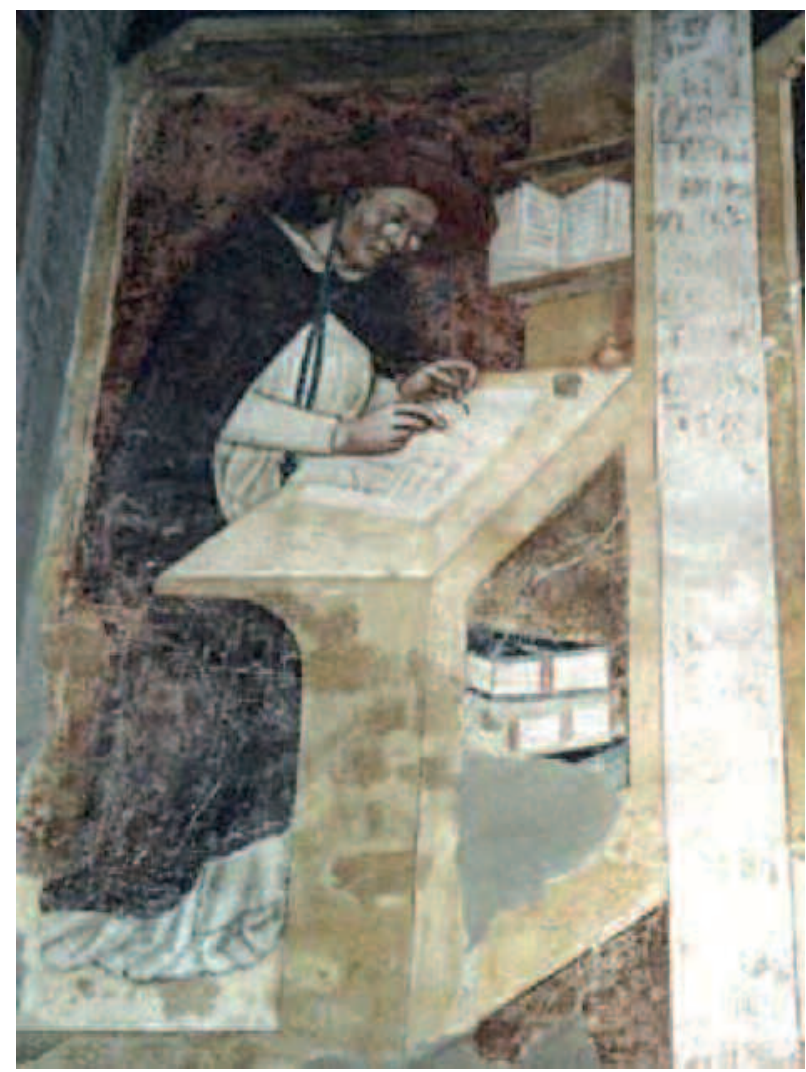

Retrato del Cardenal Hugo de Provence de Tomasso da Modena. Iglesia de San Nicolas de Treviso. Italia.

sobre 1412, poco antes de la muerte del Duque de Berry mientras que el Libro de oraciones y el misal fueron terminados a lo largo del s. XV por el Conde de Holanda, John de Bavaria, y en ellos trabajaron Jan Van Eyck y otros artistas flamencos.

Otra de las primeras antiparras se halla en una miniatura del Libro del juego de Ajedrez, también datado de finales del s. XIV. El Libro del Juego de Ajedrez de Kunrat von Ammenhausen era una traslación en verso, al alemán, de un texto en prosa más antiguo del francés Jacques de Cessoles, escrito sobre 1290. El texto alemán, realizado sobre 1337, exponía las reglas de moral y comportamiento propias de cada estamento social en el medievo, personificados en las piezas del ajedrez. Las ilustraciones que complementan el poema de Ammenhausen muestran las figuras de una partida de ajedrez a través de diferentes personajes de la sociedad y fueron realizadas mas tarde, durante los últimos años del s. XIV. Las miniaturas contienen detalles de la vida medieval y son una fuente histórica precisa, sobre todo en las representaciones de 
los peones, en los que se retratan a pequeños burgueses y campesinos.

La miniatura del Peón Octavo no es una representación fiel de la letra de Ammenhausen, que dice «tendrá los cabellos rizados y llevará en su mano derecha algunas cartas y en la izquierda tres para jugar y en la cintura un bolso», pero lo interesante para nosotros es que al lado de la figura del jugador se retrata a un monje inclinado sobre una mesa, del que se aprecian las manos y la cabeza tonsurada, atento a tres cartas boca arriba que mira con unos anteojos. Estos anteojos son los típicos primitivos unidos por un clavo central y tienen la peculiaridad de ser oscuros.

\section{BIBLIOGRAFÍA}

1. Las viejas antiparras. Laboratorios del Norte de España SA: Barcelona; 1934.

2. Voronova T, Sterligov A. Les manuscrits enluminés occidentaux du VIII au XVI siècles. Ed. Parkstone: Bournemouth (England), 1996.

3. Ascaso Puyuelo FJ, Critóbal Bescós JA. Sobre lentes, espejuelos, anteojos, gafas o antiparras. Arch Soc Esp Oftalmol 2002; 77: 689-691.

4. Simón-Tor JM, Simón-Castellví SI, Simón-Castellví G, Simón-Castellví JM, Simón-Castellví G. Los mitos sobre el origen de los anteojos (III). Arch Soc Esp Oftalmol 2004; 79: 409-411.

5. Schwartz B D. Les heures de Turín-Milán. www.liu.edu/ CWIS/CWP/LIBRARY/sc/turinmilan/turinmilan.htm 